\title{
O PIBID COMO ESPAÇO DE CONSTRUÇÃO DE SABERES DOCENTES EM UM CURSO DE LICENCIATURA EM FÍSICA
}

\section{PIBID AS A SPACE FOR THE CONSTRUCTION OF TEACHING KNOWLEDGE IN A PHYSICS DEGREE COURSE}

\author{
Alana Pereira Gimenez (alanagimenez@ hotmail.com) \\ Instituto Federal de Educação, Ciência e Tecnologia Farroupilha (IFFar) \\ Taniamara Vizzotto Chaves (taniamara.chaves@iffarroupilha.edu.br) \\ Instituto Federal de Educação, Ciência e Tecnologia Farroupilha (IFFar)
}

\begin{abstract}
Resumo: Este trabalho relata uma pesquisa que teve como objetivo investigar os reflexos do Programa Institucional de Bolsas de Iniciação à Docência (Pibid) ${ }^{1}$ na formação de professores de Física de um Instituto Federal de Educação do Estado do Rio Grande do Sul. A pesquisa foi realizada com um grupo de acadêmicos e egressos do Curso de Licenciatura em Física desta instituição. O instrumento de coleta de informações foi um questionário composto por perguntas abertas e contemplou questões relativas às principais contribuições e aprendizagens do Pibid para a formação inicial e $\mathrm{o}$ desenvolvimento profissional dos sujeitos envolvidos na pesquisa. A análise dos questionários foi realizada a luz da teoria dos saberes docentes de Tardif (2002, 2007, 2012 , 2014) e de outros teóricos do campo educacional. Constatou-se que os saberes docentes perpassaram todo o trabalho realizado pelos acadêmicos bolsistas no espaço do projeto permitindo ampliar a concepção dos mesmos sobre o trabalho docente e a identidade profissional do professor.
\end{abstract}

Palavras-chave: Pibid; Formação de professores de física; Saberes docentes.

Abstract:This paper reports a research that aimed to investigate the reflexes of the Institutional Program for Teaching Initiation Scholarships (Pibid) in the formation of physics teachers of a Federal Institute of Education of the State of Rio Grande do Sul. group of students and graduates of the Physics Degree Course of this institution. The information collection instrument was a questionnaire composed of open-ended questions and addressed questions related to Pibid's main contributions and learning for the initial education and professional development of the subjects involved in the research. The analysis of the questionnaires was performed in light of the theory of teaching knowledge of Tardif $(2002,2007,2012,2014)$ and other educational theorists. It was found that the teaching knowledge permeated all the work done by the scholarship students in the project space allowing to broaden their conception of the teaching work and the professional identity of the teacher.

Keywords: Pibid; Physics teacher training; Teaching knowledge 


\section{INTRODUÇÃO}

O presente artigo versa sobre uma pesquisa de Conclusão de Curso que procurou refletir sobre as potencialidades e os saberes produzidos a partir do espaço do Pibid no curso de Licenciatura em Física de um Instituto Federal de Educação situado no estado do Rio Grande do Sul.

O Pibid tem como meta elevar a qualidade das ações acadêmicas voltadas à formação inicial de professores nos cursos de licenciatura das Instituições de Educação Superior (IES), por meio da inserção dos licenciandos no cotidiano de escolas da rede pública de educação.

A partir do Pibid o licenciando tem a oportunidade de se inserir no contexto escolar, anteriormente ao estágio supervisionado, ou seja, desde o começo da sua formação acadêmica. Com base na Portaria 096/2013 da CAPES (Coordenação de Aperfeiçoamento de Pessoal do Ensino Superior) a inserção no ambiente escolar ocorre com a finalidade de vivenciar atividades práticas aliadas às teorias trabalhadas no espaço da formação inicial dos cursos de licenciatura, sendo este trabalho desenvolvido de forma colaborativa entre as IES e as escolas de Educação Básica.

A inserção dos acadêmicos no espaço escolar durante o processo de formação acadêmica permite reflexões "na e sobre a prática docente", sinalizando para melhorias da formação nas diversas áreas do conhecimento. Com isso, é possível observar impactos positivos junto aos cursos de formação de professores no Brasil, sobretudo, na área de Formação de Professores de Física, objeto deste artigo.

Com o objetivo de mapear as produções e os impactos relativos a presença do Pibid junto aos Cursos de Licenciatura em Física do Brasil um estudo exploratório ${ }^{2}$ realizado pelas autoras deste trabalho em 2019 junto as Atas do Simpósio Nacional de Ensino de Física (SNEF) para o período compreendido entre 2011 e 2019 permitiu mapear 142

\footnotetext{
${ }^{2} \mathrm{O}$ estudo exploratório encontra-se ainda em desenvolvimento e pretende-se também mapear os objetivos dos trabalhos socializados no SNEF, bem como as produções socializadas no Encontro de Pesquisa em Ensino de Física (EPEF) na última década. Pretende-se publicar o estudo completo no ano de 2020.
} 
produções a partir do descritor "Pibid". Foram analisados os títulos dos trabalhos e as palavras chave dos mesmos.

No estudo mencionado observou-se que aproximadamente $35 \%$ dos trabalhos produzidos e socializados dizem respeito a experiências curriculares de ensino desenvolvidas no âmbito do programa pelos diversos subprojetos, enfatizando assim o planejamento e a implementação de conteúdos curriculares no Ensino Médio; 25\% dos trabalhos estão relacionados a produção e ao uso de metodologias e recursos didáticos para o ensino de física no âmbito do Pibid; $20 \%$ teve como foco a discussão sobre a importância do Pibid para a formação inicial e continuada de professores; $14 \%$ dos trabalhos dizem respeito aos reflexos positivos do Pibid sobre a aprendizagem da física na escola e sobre as opiniões dos alunos da escola a respeito do Pibid; 5\% dos trabalhos publicados neste período teve como foco a discussão do Pibid como politica pública e, finalmente, $1 \%$ dos trabalhos encontrados permitiu associar o Pibid como espaço de formação e construção de saberes docentes.

Mediante este levantamento foi possível identificar onde estão as maiores contribuições do Pibid para a formação de professores de física nesta última década. Por outro lado, percebe-se a necessidade de ampliar as reflexões no que diz respeito à relação entre a teoria e a prática potencializada pela discussão dos saberes docentes produzidos nos espaços de formação do Programa de Iniciação a Docência.

Aliar a teoria com a prática contempla do ponto de vista teórico, o desenvolvimento dos "saberes disciplinares e dos saberes experienciais" (TARDIF, 2014). Estes contribuem, de maneira geral para a formação profissional, tanto dos acadêmicos quanto dos professores em serviço envolvidos no processo de formação a partir do Pibid.

O Edital Capes 061/2013 regulamentou o funcionamento do Pibid junto ao Curso de Licenciatura em Física do Instituto em questão. Neste sentido, entre os anos de 2013 à 2017(tomados como referência para esta pesquisa) dentre as principais ações previstas e realizadas no subprojeto Pibid-Física pode-se mencionar: promoção de oficinas didáticas com alunos e professores da Educação Básica; implementação em sala de aula dos materiais produzidos no âmbito das oficinas pelos professores das escolas com a participação dos acadêmicos bolsistas e com o acompanhamento/apoio do professor supervisor da escola; avaliação das atividades desenvolvidas tanto nas oficinas quanto 
nas aulas dos professores por meio de dois instrumentos: diários de campo e questionários; construção de diagnóstico da realidade escolar e realização de pesquisas educacionais e instrumentação de laboratórios de ciências e produção de mostras e feiras científicas.

As ações propostas durante o desenvolvimento do projeto tiveram como meta a valorização dos professores, a motivação e a promoção de práticas e experiências docentes como principal ferramenta. Também o incentivo ao uso de metodologias inovadoras, o fomento da criatividade, o contato com a comunidade escolar, a realização de trabalhos interdisciplinares e a formação continuada de professores.

Com base no levantamento do estado do conhecimento relativo às produções realizadas no Brasil durante a última década e, considerando-se a necessidade de refletir sobre os impactos do Pibid na formação inicial de professores de física do Instituto Federal a que este trabalho se vincula, entendeu-se necessário explorar e aprofundar do ponto de vista da pesquisa, como e em que medida o Pibid contribuiu para a formação e o desenvolvimento profissional dos acadêmicos de física que se vincularam ao projeto entre os anos de 2013 e 2017 procurando identificar os saberes docentes que emergiram do processo de formação a partir da participação destes no Pibid.

Assim constituíram-se os seguintes objetivos específicos desta pesquisa: "Mapear as ações, atividades e estratégias desenvolvidas no espaço do Pibid - Física, que contribuíram para o exercício da docência dos alunos que participaram do projeto"; e "Refletir sobre as potencialidades do Pibid para a formação inicial de professores de Física e a constituição de saberes relativos a docência a partir deste contexto".

A coleta de dados foi realizada por meio de um questionário aberto e a análise e sistematização das respostas encontradas foi realizada com base em referenciais teóricos da área de Educação como, por exemplo, Tardif (2002, 2007, 2012, 2014), e outros teóricos do campo educacional.

\section{INTERLOCUÇÕES TEÓRICAS}

A formação de professores tem se constituído em um campo de constante pesquisa, estudo e investigação, que exige cada vez mais, a atenção ao aspecto formativo do 
educador, ou seja, pensar a formação de professores remete a pensar à docência, suas relações e correlações.

A formação inicial é uma importante etapa na construção do ser professor, e quanto mais rica em conhecimentos e vivências, maiores são as possibilidades de formar sujeitos mais preparados para enfrentar o dia a dia da profissão, ainda mais em se tratando de áreas tradicionalmente consideradas complexas e de difícil assimilação, como no caso da Física.

Historicamente a formação de professores de Física se constitui a partir de uma constante separação entre teoria e prática, academia e escola, conhecimentos específicos e conhecimentos pedagógicos. Esta separação ou polarização tende a fortalecer a centralização na memorização de teorias e fórmulas, a compartimentação e a desarticulação entre os diferentes campos do saber que deveriam se complementar para que o processo de formação e de aprendizagem docente fosse mais integro.

Conforme Freire (1987) este tipo de ensino, deixa evidente, ainda que no espaço da formação inicial de professores, uma concepção bancária de educação, onde a relação educador-educando é fundamentalmente narradora, dissertativa, cabendo ao educador a tarefa de "encher" os educandos com os conteúdos de sua narração (p.33).

Neste sentido, o processo de ensino-aprendizagem da física acontece numa perspectiva de transmissão-recepção onde o maior prejudicado é o aluno e futuro professor que acaba por assumir uma posição passiva de receptor de conhecimentos e que ao assumir o papel efetivo de docente acaba, em determinados momentos, valendo-se da sua memória e repetindo as mesmas práticas vivenciadas no processo de formação inicial.

Romper com um ensino de física polarizado, que proporciona a dicotomia teoria e prática e que fomenta o processo de transmissão-recepção, não é um processo fácil. No entanto, acredita-se que uma saída possível seria ampliar nos espaços da formação inicial de professores as discussões relativas aos saberes docentes necessários a composição da formação e do desenvolvimento profissional docente.

Para Tardif (2014) existe um rol de saberes docentes que constituem a formação do professor, que se respeitados e considerados, podem tirar o aluno e futuro professor desta condição de apenas "transmissor" de conhecimentos de uma área especifica conhecimentos. Ou seja, o reconhecimento e o efetivo entendimento dos diferentes saberes, competências ou conhecimentos que formam o espectro docente e que permitem 
ao futuro professor a compreensão de que é necessário muito mais do que apenas saber o conteúdo especifico da matéria para poder ensinar.

Tardif (2002) compreende o saber docente como "plural, formado pelo amálgama, mais ou menos coerente, de saberes oriundos da formação profissional e de saberes disciplinares, curriculares e experienciais" (p. 36). Estes diferentes tipos de saberes tem seu ponto de partida não apenas nas Ciências da Educação ou nas disciplinas do campo específico de conhecimento que são geralmente ensinados e aprendidos no espaço da formação inicial, mas também nos saberes curriculares e práticos que na maioria das vezes são oriundos do campo de trabalho e exercício da docência.

Desta forma, conforme Tardif (2002) os saberes da formação profissional são referenciados como aqueles saberes transmitidos pelas instituições de formações de professores, ou seja, são os saberes produzidos pelas ciências da educação destinados à formação científica ou erudita dos professores.

Os saberes disciplinares são aqueles que correspondem aos diversos campos do conhecimento e emergem da tradição cultural e dos grupos sociais produtores de saberes. Por exemplo, aqueles oriundos da matemática, da física, da história, da geografia etc. São saberes que a sociedade dispõe, tais como se encontram hoje integrados na universidade sob forma de disciplina.

Os saberes curriculares estão relacionados aos programas escolares (objetivos, conteúdos, métodos) que os professores necessitam aprender e aplicar. Correspondem aos discursos, objetivos, conteúdos e métodos que a instituição escolar seleciona como modelo da cultura erudita e de formação para essa cultura. Apresentam-se concretamente sob a forma de programas escolares que os professores devem conhecer e desenvolver.

Por fim, os saberes da experiência podem ser considerados como aqueles desenvolvidos no exercício e na prática da profissão, que emergem da experiência e são avaliados por ela. Tais saberes se constituem como um conjunto de representações onde o professor interpreta, compreende e orienta a sua profissão em todas as dimensões. Brotam da experiência e são por ela validados. Incorporam experiência individual e coletiva, sob forma de habitus e de habilidades, de saber-fazer e de saber-ser.

Gauthier et al. (2006) consideram que a mobilização de diferentes saberes os quais formam uma espécie de reservatório, permitem que o professor se abasteça no sentido de responder às exigências específicas de sua situação concreta de ensino (p.28). Esta 
concepção põe em evidência a importância de que na formação inicial de professores sejam identificados e explorados os diferentes saberes docentes que permitem de forma dinâmica, a reposição, a manutenção, a avaliação, a promoção de análises, reflexões e reformulações das práticas durante toda a vida profissional docente.

De maneira geral, a construção da docência é composta por saberes docentes que começam a se constituir na formação inicial docente, e que se prolongam por toda a vida profissional. Neste sentido, há de se pensar a formação inicial de professores levando em conta os saberes docentes e o contexto escolar, sendo que o licenciando, ao se inserir no espaço escolar desde o princípio da sua graduação e não apenas no momento do estágio curricular tem a oportunidade de desenvolver atividades didático-pedagógicas, bem como experienciar momentos que possibilitem a construção de novos saberes, muitas vezes não desenvolvidos no espaço acadêmico, pois advém da prática e da experiência.

A criação de espaços que permitam articular os diferentes saberes e experienciar práticas reflexivas é fundamental nos cursos de formação inicial de professores. Pesquisas nas mais diversas áreas do conhecimento relacionadas a formação de professores tem sinalizado quanto a importância do Pibid como espaço de melhoria da formação inicial.

São espaços como este que permitem aliar os conhecimentos teóricos e acadêmicos, construídos ao longo do processo de formação inicial docente, aos saberes da experiência vivenciados no espaço escolar mostrando que a articulação dos saberes oriundos dos diversos campos de conhecimento define e interfere tanto na formação quanto no desenvolvimento profissional docente.

\section{METODOLOGIA}

O presente trabalho trata-se de uma pesquisa de caráter qualitativo, onde buscou-se fazer uma reflexão sobre as contribuições do Pibid, para a formação inicial e continuada de professores de física de um Instituto Federal de Educação localizando no estado do Rio Grande do Sul.

Conforme D’ambrósio e D'ambrosio (2006)

A pesquisa qualitativa [...] tem como foco entender e interpretar dados e discursos, mesmo quando envolve grupos de participantes. [...] Ela depende da relação observador- observado, [...] A sua metodologia de trabalho por 
excelência repousa sobre a interpretação e várias técnicas de análise de discurso.

Para tanto, utilizou-se como instrumento de coleta de informações um questionário composto por perguntas abertas. $\mathrm{O}$ instrumento contemplou questões relativas às principais contribuições e aprendizagens do projeto para a formação inicial e o desenvolvimento profissional.

Os sujeitos da pesquisa são os egressos do Curso de Licenciatura que participaram como bolsistas do Pibid bem como os acadêmicos que ainda não concluíram o curso, mas que tiveram participação junto ao Pibid em algum momento da sua formação.

A pesquisa foi desenvolvida a partir das seguintes ações: mapeamento e seleção dos bolsistas vinculados ao curso e que participaram do projeto; elaboração do TECLETermo de Consentimento Livre e Esclarecido e cadastro do projeto de pesquisa junto a Plataforma Brasil; construção do questionário aberto, o qual contemplou 8 (oito) perguntas ao todos, sendo 5 (cinco) perguntas discursivas e 3 (três) objetivas; contato com os acadêmicos egressos do Pibid e envio do convite para participação da pesquisa; compartilhamento e aplicação do questionário por meio da ferramenta Google Forms ${ }^{3}$ e, finalmente sistematização e análise das respostas obtidas a luz do referencial teórico. Para a sistematização e análise partiu-se de categorias de análise que emergiram das respostas dos sujeitos da pesquisa.

Após a organização e a sistematização procurou-se aproximar as respostas dadas pelos sujeitos participantes da pesquisa considerando-se respostas com semelhanças de tal forma que foram constituídas algumas categorias de análise vinculadas a cada questão.

\section{RESULTADOS E DISCUSSÃO}

O texto a seguir foi sistematizado e organizado considerando-se as questões 01 a 05 propostas no questionário. Tais questões foram escolhidas, pois permitem refletir sobre os saberes docentes que perpassaram as práticas desenvolvidas no espaço do Pibid. Assim

\footnotetext{
3 O Google Forms é um serviço gratuito para criar formulários online. Nele, o usuário pode produzir pesquisas de múltipla escolha, fazer questões discursivas, solicitar avaliações em escala numérica, entre outras opções. Permite ainda criar questionários e também acompanhar as respostas.
} 
as questões analisadas tratam aspectos como: relevância do Pibid para a formação dos professores de física e para a formação pessoal dos acadêmicos egressos; aprendizagens adquiridas com o Pibid; formas de valorização docente presentes na proposta do Pibid e saberes docentes vivenciados durante o processo de formação no espaço do Pibid.

A primeira questão analisada teve como objetivo identificar a relevância do Pibid para a formação de professores. De acordo com as respostas dos bolsistas foi possível constatar que o Pibid contribui, de maneira geral, para formação inicial e para a formação continuada dos professores de física envolvidos no programa. Também foi sinalizada a importância do programa, especificamente para o desenvolvimento dos estágios curriculares durante o processo de formação inicial.

Neste sentido, percebe-se que teoria e prática estão intimamente relacionadas e que a Escola é colaboradora da Universidade no processo de articulação entre a teoria e a prática. Portanto, não se faz formação de professores apenas do ponto de vista teórico no espaço da Universidade, mas sim de forma colaborativa com a Escola no espaço da prática pedagógica, conforme explicitado na resposta do sujeito 11, a seguir:

[...] creio que de unir a teoria apresentada na universidade com a prática nas escolas públicas, porque assim o amadurecimento em relação ao ensino aprendizagem virá ainda em período de graduação, além de estarem familiarizados com seu futuro ambiente de trabalho. ( Sujeito 11)

Esta concepção é legitimada por Tardif (2014) quando assume que os Saberes Disciplinares, desenvolvidos durante a formação inicial no espaço das universidades, que dizem respeito às disciplinas cursadas, aos conhecimentos específicos da área de formação necessitam estar em consonância com os saberes curriculares e os experienciais construídos durante a prática pedagógica escolar.

A contribuição do Pibid para com a formação continuada de professores de física pode ser verificada também na fala dos acadêmicos. Assim, conforme o sujeito 09 .

O programa visa melhorar o ensino nas escolas públicas, bem como proporcionar aos futuros professores experiências metodológicas, tecnológicas e práticas docentes. Assim, os acadêmicos estarão inseridos no cotidiano das escolas desenvolvendo atividades didático-pedagógicas.

Neste sentido, conforme Lima (2001, p.11); 
A formação contínua estaria assim, a serviço da reflexão e da produção de um conhecimento sistematizado, capaz de oferecer a fundamentação teórica necessária para articulação com a prática criativa do professor com relação ao aluno, à escola e à sociedade. Estaria ainda ajudando a pensar a profissão, a profissionalização, o profissionalismo e o desenvolvimento profissional do professor.

Finalmente, conforme o sujeito 10 as contribuições do Pibid para com o estágio supervisionado se dão na medida em que.

[...] o Pibid proporciona aos alunos a oportunidade de participar de um projeto que é muito relevante, pois coloca o aluno futuro professor no ambiente escolar, em contato com os alunos, com situações corriqueiras da profissão docente. Este tipo de experiência faz total diferença para quando o aluno entra em período de estágio curricular supervisionado, pois o aluno pibidiano já tem segurança para assumir uma turma. Além disso, o PIBID dá uma visão ampla do que é ser professor, e que o ensinar vai muito além do ambiente da sala de aula. (Sujeito 10)

Percebe-se por meio da fala do Sujeito 10 a importância de se articular o que Tardif (2014) chama de Saberes Curriculares, adquiridos com a vivência escolar, e os Saberes Experienciais, ou seja, aqueles desenvolvidos durante e com a prática do professor, através de suas experiências cotidianas, sua interação com o meio, suas relações pessoais e profissionais. Estes saberes legitimam o fazer docente.

A segunda questão teve como objetivo identificar o que o Pibid representou na construção do processo de formação dos bolsistas envolvidos.

De acordo com as respostas dos bolsistas foi possível identificar quatro distintas categorias, ou seja, a primeira relacionada a construção da identidade profissional do professor, a segunda relacionada a aquisição de experiência profissional, a terceira considerando-se a possibilidade de relacionar teoria e prática e finalmente como possibilidade de repensar o ensino da física de forma tradicional na Educação Básica.

A construção da identidade profissional emerge na fala do sujeito 10, conforme explicitado a seguir,

[...] foi o pontapé inicial para que eu entendesse o que é ser um bom professor, não apenas falando sobre a prática docente. Foi no Pibid onde comecei a perceber a importância do planejamento, do convívio em grupo, da responsabilidade que o professor tem perante seus alunos. ( Sujeito 10)

De acordo com Garcia: 
A construção da identidade profissional inicia durante o período de estudante nas escolas, mas se consolida logo na formação inicial e se prolonga durante todo seu exercício profissional. Essa identidade não surge automaticamente como resultado da titulação; ao contrário, é preciso construí-la e modelá-la. E isso requer um processo individual e coletivo de natureza complexa e dinâmica, o que conduz à configuração de representações subjetivas acerca da profissão docente (2010, p.18).

Pimenta (2008) faz referência à questão da construção da identidade profissional, afirmando que,

[...] essa identidade não é um dado imutável, mas é um processo de construção do sujeito historicamente situado. Ela se constrói a partir da significação social da profissão, da revisão constante dos significados sociais da prática, da revisão das tradições e da reafirmação de práticas consagradas culturalmente e que permanecem significativas (p. 19).

Para o sujeito 02, a aquisição de experiência profissional,

[...] representou e ainda representa qualificações múltiplas no processo de ensino aprendizagem. Pois me garantiu vivenciar experiências que me fizeram evoluir como graduando do curso de licenciatura em Física, como principalmente na perspectiva de futuro professor dentro da área de ensino. (Sujeito 2).

Segundo Tardif (2014, p. 39), “esses saberes brotam da experiência, são por ela validados. Eles incorporam-se à experiência individual e coletiva sob a forma de habitus e habilidades, de saber-fazer e de saber-ser". Percebe-se esta perspectiva teórica na fala do sujeito 02 acima mencionada e, percebe-se também a consciência adquirida pelo sujeito sobre a importância que a experiência de Pibidiano terá na sua formação e desenvolvimento profissional.

A relação entre teoria e prática transparece novamente a partir desta questão. Assim, conforme as falas dos sujeitos 09 e 11 o Pibid,

[...] representou um fortalecimento na minha formação, se o PIBID não existisse, teria contato como ambiente escolar apenas nos últimos semestres do curso, no estágio, com o Pibid obtive a oportunidade de entrar no ambiente escolar antes, articulando a teoria de ensino com a prática docente, potencializando minha formação. (Sujeito 09)

[...] sem dúvida alguma, é um projeto que representou para minha formação não somente a qualidade da minha formação, como foi a ponte entre a universidade e realidade da educação pública, me proporcionando conhecimento prático daquilo que eu teria no meu dia-a-dia quando graduada. ( Sujeito 11) 
A inserção e a interlocução dos licenciandos com a realidade escolar contribui para uma formação docente mais sólida, contextualizada, reflexiva da, na, sobre a prática (FREIRE, 1987), aproximando-os, desde o início da formação inicial, ao contexto da prática cotidiana das escolas de educação básica, perpassando pelas etapas do planejamento, desenvolvimento e avaliação da ação educativa. Neste contexto, o Pibid serviu como espaço articulador e dinamizador para que a interlocução entre os saberes oriundos da formação inicial e os saberes oriundos da prática pedagógica acontecessem, fortalecendo e construindo novos saberes profissionais docentes.

Finalmente, a participação no Pibid possibilitou refletir e pensar sobre o ensino de física da escola tradicional, pontuando a importância de um ensino de física pautado em formas e metodologias alternativas conforme explicitado pelo sujeito 07 “ “...] possibilitou uma troca de experiências com toda a equipe envolvida a respeito de como planejar e implementar atividades lúdicas que despertem o interesse e a curiosidade dos alunos sobre Física”.

Neste sentido, Ramos (2012) afirma que é por meio das atividades lúdicas, que o indivíduo forma conceitos, seleciona ideias, estabelece relações lógicas, integra percepções e se socializa. Sendo assim, o ensino de física passa a fazer mais sentido para o aluno na medida em que proporciona uma formação integral e ampla, não apenas conteudista.

Finalmente evidenciou-se a perspectiva da aprendizagem docente individual por meio da experiência coletiva, das interações entre os diferentes sujeitos no mesmo espaço social ou cultural. Conforme Vygotsky apud Moreira (2017) os processos mentais superiores (pensamento, linguagem, comportamento, atenção consciente, memória voluntária, etc.) têm origem em processos sociais e são a conversão de relações sociais em funções mentais. Neste sentido, o Pibid se configurou como espaço coletivo de aprendizagem docente e transformações cognitivas.

A questão três teve como objetivo identificar as aprendizagens adquiridas com o Pibid pelos egressos e bolsistas.

Neste contexto, de acordo com as respostas dos bolsistas e egressos foi possível perceber que o Pibid proporcionou aprendizagens que estão relacionadas, segundo os respondentes aos seguintes aspectos: diferentes metodologias de ensino; planejamento 
didático, trabalho em equipe, responsabilidade e comprometimento, escrita formal e acadêmica e postura como professor.

Quanto as "diferentes metodologias de ensino", ficou evidente a importância do desenvolvimento de atividades lúdicas com o uso de materiais e recursos variados e de baixo custo.

Acredita-se que o trabalho com diferentes recursos metodológicos e materiais de baixo custo, podem despertar no professor a capacidade de pensar e criar seus próprios materiais de ensino e, no aluno, a possibilidade de aprender pela diversidade de uso de materiais. São muitas as possibilidades de uso de recursos metodológicos de ensino, por exemplo, a experimentação, a leitura de textos didáticos e não didáticos, a história da física, a resolução de problemas, os jogos entre outros. Todos apresentam diferentes potencialidades de ensino e podem despertar diferentes capacidades e habilidades.

Quanto ao planejamento conforme explicitado na afirmativa do sujeito 03 " [...] durante o curso aprendemos a planejar, mas a minha primeira experiência foi com o PIBID, planejar para a aprendizagem do aluno, pensar nos mínimos detalhes para propor o melhor aos alunos".

Conforme Libâneo (1991) o planejamento pode ser entendido como um processo de sistematização e organização das ações do professor, como um instrumento da racionalização do trabalho pedagógico que articula a atividade escolar com os conteúdos do contexto social. Assim, o ato de planejar a prática pedagógica desperta para distintas potencialidades e saberes relativos à construção da prática docente.

A "responsabilidade e o comprometimento", também foram mencionados como aprendizagens adquiridas, conforme explicitado na fala do sujeito 10, o qual destaca “[...] cumprimento de horários, reuniões semanais, entrega de relatórios mensais, planejamentos de projetos e comprometimento para com os outros envolvidos".

Acredita-se que todos os elementos mencionados pelo sujeito 10, tem contribuição primordial para a formação docente, especialmente para a construção da responsabilidade, do comprometimento e da autonomia para com a atividade docente. Todos estes aspectos contribuem para a complementação e a valorização da formação profissional docente, como relatado por Francischett et al (2012), 
A partir da vivência que o programa possibilita com o cotidiano escolar, com suas dinâmicas, seus problemas e, principalmente, com seus sujeitos (o contato denso, intenso e prolongado), o medo da desvalorização profissional vai, aos poucos, sendo substituído pela construção do compromisso e da responsabilidade docente. (p. 22).

Finalmente o "trabalho em equipe" também é destacado como uma aprendizagem adquirida no espaço do Pibid. Esta aprendizagem fica explícita a partir da fala do sujeito 10, segundo o qual "[...] éramos um grupo de sete pessoas, todas as atividades eram divididas, na escrita de trabalhos, por exemplo, todos colaboravam a fazer sua parte [...] importância de saber ouvir e respeitar as opiniões dos outros, buscando os melhores resultados".

Diante deste contexto conforme Chaves (2018),

O trabalho realizado de forma coletiva no espaço do grupo demarcado por relações de confiança e afetividade entre os diferentes sujeitos e pelas discussões desencadeadas a partir dos problemas da realidade midiatizados pela teoria que balizou as ações do grupo constitui-se num espaço fundamental para o empoderamento dos diferentes sujeitos participantes do grupo no que diz respeito à construção da própria docência. (p. 62- 63)

Percebe-se assim que o Pibid constituiu-se como um espaço de construção individual e coletiva, de promoção da autoconfiança e do autoconhecimento. Este tipo de abordagem e construção coletiva permite que as fraquezas sejam minimizadas e que as potencialidades sejam maximizadas.

Neste sentido, as trocas de experiências realizadas contribuem para a formação de saberes experienciais, na medida em que são desenvolvidos durante e com a prática do professor, através de suas experiências cotidianas, sua interação com o meio, suas relações pessoais e profissionais e acabam se legitimando no próprio fazer docente.

A "escrita formal e acadêmica", também foi mencionada como aprendizagem construída conforme explicitado pelo sujeito 08 “[...] participar de eventos educacionais de âmbito local, regional e nacional. [...] incentiva a escrita e apresentações científicas. [...] foram escritos projetos, artigos, atas, relatórios e outros documentos que exigiam padrão de escrita a nível acadêmico".(Sujeito 8)

Neste sentido, a fala do sujeito 08 a mostra a importância atribuída ao Pibid como espaço de produção de diferentes documentos, que permitiram o fomento a produção e a produtividade, fazendo com que não apenas se pensasse a prática e os saberes a ela 
relacionados, mas que se estivessem reflexões, registros e a socialização sobre as práticas desenvolvidas no âmbito do grupo.

A "postura como professor" também foi evidenciada como uma aprendizagem construída. Neste sentido conforme o sujeito 08 o programa proporcionou "[...] uma primeira introdução em sala de aula como docente (ou equivalente), foi possível constatar que é necessário um bom relacionamento com a turma, porém ao mesmo tempo é necessário "controle" para que não ocorra desordem demasiada."

Fica evidente na fala do sujeito 08 que é preciso que os professores despertem a paixão dos educandos, tecendo uma teia de aprendizado contínuo de ação e reflexão, "a prática docente crítica, implicante do pensar certo, envolve o movimento dinâmico, dialético, entre o fazer e o pensar sobre o fazer" (FREIRE, 1996, p.38).

A quarta questão teve como objetivo identificar como e se os sujeitos percebem a valorização docente nas proposições do Pibid. Neste sentido, observou-se que o programa serviu como um instrumento de incentivo, uma ferramenta de motivação e valorização conforme explicitado na fala do sujeito 08 ,

[...] as pessoas entram no curso de licenciatura em Física sem realmente saber do que o curso se trata e, conforme o andar dos semestres, as pessoas acabam desistindo por não se identificarem com o curso. O Pibid é uma ferramenta de motivação neste sentido, pois temos uma bolsa que nos possibilita permanecer no curso e arcar com gastos que provém do mesmo, e o fato de podermos atuar em escolas do município valoriza o nosso curso e a profissão professor, pois a partir das atividades desenvolvidas nas escolas parceiras que realmente percebemos a carência existente no quesito de professores qualificados e formados em Física [...]. Portanto, o Pibid é muito eficiente no que diz respeito a valorização e qualificação de professores, pois o programa nos dá a oportunidade de nos qualificarmos desde o início do curso [...] valorizamos muito mais a nossa profissão e somos valorizados. (Sujeito 08)

Neste contexto, percebe-se a importância do Pibid como espaço de permanência e êxito bem como de valorização profissional no que se refere a formação para a Licenciatura em Física. Na medida em que oferta uma bolsa aos acadêmicos para estarem em processo de formação permanente, o Pibid permite que os acadêmicos se integrem ao programa por completo sem a perspectiva de realização de outro tipo de trabalho remunerado, podendo assim, investir integralmente na formação inicial.

Também fica evidente a ampliação das perspectivas de trabalho aos acadêmicos, de abertura de oportunidades já que os mesmos se inserem na prática desde o início do curso 
acompanhados por professores da escola e da instituição de formação inicial que trabalham de forma colaborativa.

Finalmente, entende-se o Pibid como espaço de desenvolvimento profissional da e pela pesquisa dadas as características do projeto desenvolvido na escola.

Conforme Santos (2013),

[...] para efetivar a prática da pesquisa na educação básica é necessário que os docentes tenham a pesquisa no seu processo de formação como um componente que se efetive como espaço de reflexão crítica do exercício da docência e da realidade da educação básica, visando à construção de saberes que servirá de suporte aos acadêmicos, futuros professores para o desenvolvimento de uma postura investigativa na sua prática profissional (p. 162).

A quinta e última questão analisada nesta pesquisa, teve como objetivo identificar os saberes docentes presentes nas experiências e práticas desenvolvidas no Pibid. Assim os Pibidianos foram desafiados a pensar quais saberes docentes perpassaram as práticas desenvolvidas no espaço do Pibid, considerando-se a tipologia de sabres de Tardif (2002). Neste sentido observou-se nas respostas a presença de todos os saberes docentes mencionados por Tardif (2002), a saber: saberes da formação profissional, saberes disciplinares, saberes curriculares e saberes da experiência (ou práticos).

Conforme Tardif (2002), os quatro tipos diferentes de saberes implicados na prática docente acima mencionados

“[...] apresentam-se como doutrinas ou concepções provenientes de reflexões sobre a prática educativa no sentido amplo do termo, reflexões racionais e normativas que conduzem a sistemas mais ou menos coerentes de representação e de orientação da atividade educativa" (TARDIF, 2007, p. 37).

Portanto, é evidente a importância que os saberes docentes têm na prática do professor, pois os mesmos se apresentam como uma forma do professor refletir acerca da sua prática profissional e, a partir disso, ponderar se seus objetivos como educador estão sendo alcançados ou não.

\section{CONSIDERAÇÕES FINAIS}


A partir do presente trabalho foi possível identificar a importância do Pibid - Física como espaço de construção e validação de diferentes saberes docentes. Os diferentes saberes foram vivenciados pelos acadêmicos e egressos na medida em que se promoveu um espaço de formação em que as ações desenvolvidas primaram pelo desenvolvimento de práticas reflexivas e de ações consensuadas onde os saberes disciplinares foram validados pelos saberes da experiência.

O Pibid- Física se constituiu num espaço de desenvolvimento das mais diversas habilidades tais como o trabalho coletivo, a produção escrita, a criação de estratégias de ensino inovadoras, o planejamento da ação pedagógica o que possibilitou desvelar e minimizar dificuldades e necessidades, estabelecer trocas e reflexões entre os diferentes participantes.

Neste sentido, os acadêmicos puderam vivenciar um espaço onde os diferentes saberes encontraram-se imbricados o tempo todo, onde as vivências das diferentes situações que envolveram estudos e discussões conceituais e metodológicas, situações relacionadas ao cotidiano escolar e aos alunos da Educação Básica, situações relacionadas ao contexto da educação em geral, do programa escolar da disciplina de física e dos problemas vivenciados pelos professores na escola fortaleceram a sua formação e permitiram perceber que não é possível pensar o planejamento e o exercício da docência apenas a partir dos saberes disciplinares.

Neste sentido, a presença de professores colaboradores das escolas parceiras auxiliou na validação e na construção dos saberes dos acadêmicos, mostrando o quanto é importante e são significativas ações colaborativas entre as IES e as Escolas de Educação Básica, especialmente no que se refere à construção da identidade docente.

Os resultados encontrados demonstram que o Pibid contribui para a valorização da profissão docente e para o aumento da qualidade na formação de professores, na medida em que este espaço contribuiu para reflexões sobre a importância da realização de práticas docentes pensadas e articuladas, ou seja, que o trabalho docente não pode ser realizado por qualquer pessoa que não esteja preparada para tanto. Também, na medida em que a formação inicial quando aliada a formação continuada de professores em serviço permite desvelar e compreender qual o papel do trabalho docente no processo de ensino- 
aprendizagem, refletindo na melhoria das práticas, no desenvolvimento profissional docente e, sobretudo na aprendizagem dos alunos no espaço escolar.

Finalmente, a análise realizada a luz do referencial teórico adotado mostrou que este trabalho traz importantes contribuições, pois permite refletir sobre os impactos do Pibid na formação de professores de física com base na teoria dos saberes docentes sendo esta perspectiva teórica pouco explorada em trabalhos e publicações que retratam o Pibid no decorrer da última década no Brasil.

\section{REFERENCIAS}

BRASIL. Ministério da Educação. Regulamento do Programa Institucional de Bolsa de Iniciação à Docência. Portaria n ${ }^{\circ}$ 096, de 18 de julho de 2013. Disponível em http://www.capes.gov.br/images/stories/download/legislacao/Portaria_096_18jul13_Apr ovaRegulamentoPIBID.pdf. Acesso: 04 Nov. 2018.

BRASIL, M. D. E. Diretoria de Formação de Professores da Educação Básica. DEB (Resumo Executivo do Relatório de Gestão 2009-2013).

CHAVES, T. V.; GIMENEZ, A. P.; VIEIRA, D. W. Espaços coletivos de formação inicial e continuada de professores: ressignificando práticas educativas por meio do trabalho colaborativo no Pibid Subprojeto de Física. In: BRUM NETO, H.; UBERTI, H. G.; TONIOLO, J.M. dos S. de A. PIBID IF FARROUPILHA: ações articuladas para a excelência da/na formação de professores. São Leopoldo: Editora Oikos, 2018.

D’AMBRÓSIO, B. S.; D’AMBROSIO, U. Formação de professores de matemática: professor-pesquisador. Atas de pesquisa em Educação, v. 1, n. 1, p. 75-85, 2006.

FRANCISCHETT, M. N.; GIROTTO, E. D.; MORMUL, N. M. O PIBID como política pública de permanência no Ensino Superior e de formação de professores: um estudo de caso. Educare et. Educare. v.7, n 13, Cascavel, 2012.

FREIRE, Paulo. Pedagogia do oprimido. 17. ed, Rio de Janeiro: Paz e Terra. Coleção O mundo de hoje, v.21. 1987.

FREIRE, Paulo. Pedagogia da autonomia: saberes necessários à prática educativa. 23.ed. São Paulo: Paz e Terra, 1996.

GARCIA, C M. O professor iniciante, a prática pedagógica e o sentido da experiência. Formação Docente, Belo Horizonte, v. 02, n. 03, p. 11-49, ago./dez. 2010.

GAUTHIER, C. et al. Por uma teoria da pedagogia: pesquisas contemporâneas sobre o saber docente. 2. ed. Ijuí: Unijuí, 2006. 
LIBÂNEO, José Carlos. Didática. São Paulo: Cortez, 1991.

LIMA, Maria do Socorro Lucena. A formação contínua do professor nos caminhos e descaminhos do desenvolvimento profissional. Doutoramento em Educação USP, São Paulo: 2001.

MOREIRA, Marco Antônio. Teorias de Aprendizagem. 2. ed. São Paulo: EPU, 2017.

PIMENTA, S. G. Saberes pedagógicos e atividade docente. 6.ed. São Paulo: Editora Cortez, 2008.

RAMOS, Fábio. A importância do lúdico no processo de aprendizagem. Disponível em: http://fabiopestanaramos.blogspot.com/2012/02/importancia-do-ludico-no-processo-de.htm Acesso em: 24 out. 2018.

SANTOS, M. F. P. dos. A relação teoria-prática no estágio supervisionado em Geografia. In: CASTROgIOVANNI, A. C, TONINI, I, M; KAERCHER, N. A. (Orgs). Movimentos no ensinar Geografia. Porto Alegre: Imprensa Livre: Compasso Lugar Cultura, 2013.

TARDIF, Maurice. Saberes docentes e formação profissional. 4 ed. Rio de Janeiro: Vozes, 2002.

TARDIF, Maurice. Saberes docentes e formação profissional. 8 ed. Petrópolis: Vozes, 2007.

TARDIF, Maurice. Saberes docentes e formação profissional. 14 ed. Petrópolis: Vozes, 2012.

TARDIF, Maurice. Saberes docentes e formação profissional. 17ed. Petrópolis: Vozes, 2014. 